\title{
Origin of collapsed pits and branched valleys surrounding the Ius chasma on Mars
}

\author{
Gasiganti T. Vamshi, Tapas R. Martha and K. Vinod Kumar \\ National Remote Sensing Centre (NRSC), Hyderabad, India - gtvamshi@gmail.com, (tapas_martha, vinodkumar_k)@nrsc.gov.in
}

\author{
ISPRS Technical Commission VIII Symposium
}

KEY WORDS: Valles Marineris, MEX, HRSC

\begin{abstract}
:
Chasma is a deep, elongated and steep sided depression on planetary surfaces. Several hypothesis have been proposed regarding the origin of chasma. In this study, we analysed morphological features in north and south of Ius chasma. Collapsed pits and branched valleys alongwith craters are prominent morphological features surrounding Ius Chasma, which forms the western part of the well known Valles Marineris chasma system on Martian surface. Analysis of images from the High Resolution Stereo Camera (HRSC) in ESA's Mars Express (MEX) with a spatial resolution of $10 \mathrm{~m}$ shows linear arrangement of pits north of the Ius chasma. These pits were initially developed along existing narrow linear valleys parallel to Valles Merineris and are conical in shape unlike flat floored impact craters found adjacent to them. The width of conical pits ranges 1-10 km and depth ranges 1-2 km. With more subsidence, size of individual pits increased gradually and finally coalesced together to create a large depression forming a prominent linear valley. Arrangement of pits in this particular fashion can be attributed to collapse of the surface due to large hollows created in the subsurface because of the withdrawal of either magma or dry ice. Branched valleys which are prominent morphologic features south of the Ius chasma could have been formed due to groundwater sapping mechanism as proposed by previous researchers. Episodic release of groundwater in large quantity to the surface could have resulted in surface runoff creating V-shaped valleys, which were later modified into U-shaped valleys due to mass wasting and lack of continued surface runoff.
\end{abstract}

\section{INTRODUCTION}

Ius Chasma is one of several chasmata that make up Valles Marineris, which is the largest chasma system in the solar system. Ius Chasma is bounded to the north and south by higher standing wallrock and the floor is covered by dunes that are oriented approximately north-south. A dense valley system is present in north and south of Ius chasma. The objective of this paper is to explain possible origin of these valley networks. The formation of these valleys might have started during late Noachian and Hesperian periods. These kind of valley networks were first discovered in southern highlands and led researchers to believe an early warm and wet Martian climate having surface runoff due to precipitation (Pieri 1976; Pollack et al 1987). Evidences of fluvial process were also found through alluvial fans with valley meanders (Malin and Edgett, 2003; Moore et al.,2003) and crossbedding structures at Meridiani Planum which were earlier thought to be formed by surface water currents (Squyres et al., 2004).

Based on these morphological observations, tectonic, surface water erosion and ground water erosion models were proposed to explain the origin of branched valleys. The hypotheses based upon tectonic models (Lucchitta, 1989) were related to tensional stresses associated with the formation of Tharsis dome (Wise et al., 1979). Some other proposed tectonic models include rifting along a ridge distinct from the Tharsis bulge (Frey, 1979), magma withdrawal causing collapse (Sharp, 1973; Scott and Tanaka, 1986) or tensional fracturing at depth (Tanaka and Golombek, 1989). Some other evidences were also found such as wall retreat and erosion along structural lines of weakness, especially in tributary chasmas, indicating a combination of tectonic and erosional processes (Masson, 1985). Other hypothesis of valley formation are sapping processes, ice-lubricated creep, sublimation, subsurface drainage (Lucchitta et al., 1989) or karst collapse (Croft, 1989; Battistini,1990).

In this study, we presented new morphological observations that supports groundwater sapping as the most likely cause of the formation of branched valley networks south of Ius chasma (Figure 1). The branched valleys enter the chasma from the south. Most of valley networks also display further surface degradational activities such as impact cratering, aeolian and ice-related processes.

\subsection{GEOLOGY OF IUS CHASMA}

The Ius chasma most likely formed with activities those were associated with the development of the Tharsis plateau and volcanoes to the west. The chasma is approximately 900 kilometers long and is located in western part of Valles Marineris. The floor of Ius Chasma is between 8 to 10 kilometers deep. Impact craters, Wind, mass wasting processes and glaciers possibly water have modified the chasmata after they were formed. Layered deposits and bright patches of material can also be found in and around Ius chasma floor. The layered deposits appear distinct in morphology from the nearby wall rock. These layered deposits might have formed due to atmospheric dust, sand or silt of an ancient water source. The ejecta of small fresh-appearing impact craters formed in the light-toned deposits reveal the existence of basalt. 


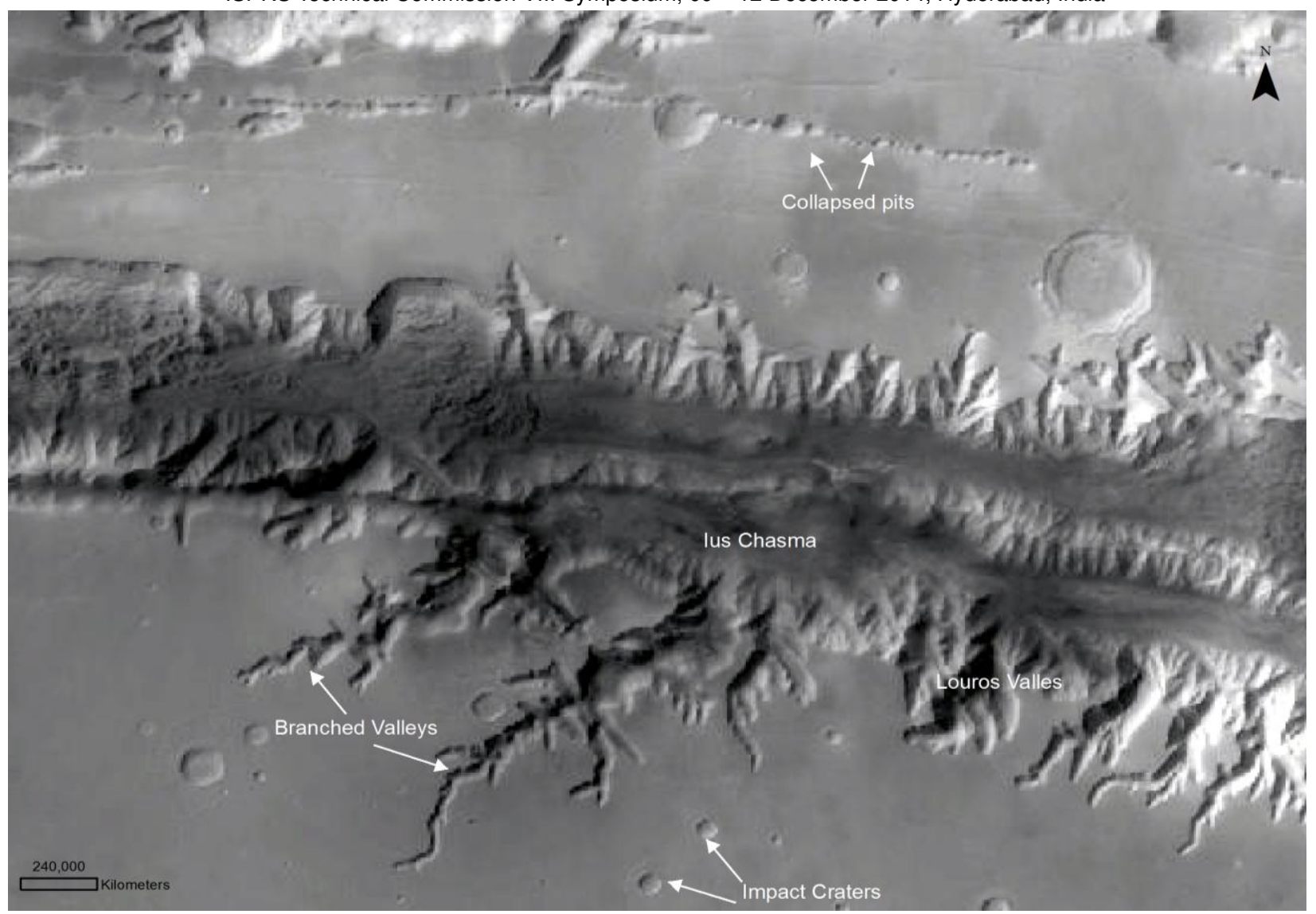

Fig .1 Mars Global Surveyor (MGS) Mosaic of Ius Chasma showing branched valleys and linearly arranged pits in south and north of Ius Chasma, respectively.

\section{DATA USED}

Remote sensing data are the major source for our current understanding of the geologic evolution of Mars in qualitative and quantitative terms. Therefore, a prime objective of the Mars Express orbiter is the photogeologic analysis of the Martian surface at high resolution. Satellite imagery in the 10 $\mathrm{m}$ pixel range as obtained by the High Resolution Stereo Camera (HRSC) in the Mars Express (MEX), produced Digital Terrain Models (DTMs) which were essential prerequisite for detailed surface morphological exploration. We have also used Mars Global Surveyor (MGS) mosaic generated by Malin Space Science Systems (MSSS) and Arizona State University (ASU) using MGS's Mars Orbiter Camera (MOC) and High Resolution Imaging Science Experiment (HIRISE) data (0.3 $\mathrm{m} /$ pixel) from Mars Reconnaissance Orbiter (MRO). HIRISE images were useful to indentify small size landforms on Martian surface.

\section{OBSERVATIONS}

\subsection{Branched Valleys}

The channel and valley networks of Mars are exciting geomorphic features discovered by Mariner and Viking missions (Baker, 1982). The resemblance and scale of valley networks to terrestrial valley systems created primarily by surface runoff prompted earlier researchers to conclude that branched valleys were formed by runoff that occurred in Martian period. The valley networks were initially called as gullies (Milton, 1973), arroyo (Hartmann, 1974) and runoff channels (Sharp and Malin, 1975) and only recently the term valley networks was used by (Baker, 1982). Groundwater erosion and sapping processes might have dominated in large individual branched valleys, which are distinguished from the highlands dendritic networks by uniform width, and few, poorly developed tributaries (Laity and Malin, 1985; Kochel and Piper 1986). The drainage basin is densely dissected with many well developed tributaries, suggesting the influence of surface runoff. The sapping channels that comprise Louros Valles along the southern wall have two preferred orientations (Kochel and Piper, 1986). These orientations might suggest the structural control that influences both the sapping channels and fracturing along the chasma (Kochel and Piper, 1986). The creation of structural weaknesses exploited by sapping channels and other fracturing is thought to predate the formation of Valles Marineris (Tanaka, 1986). The chasma tributaries south of Ius Chasma are seen joined by shallow, dendritic valley network trunk from the adjacent plateau. The high resolution HRSC image shows that the shallow valley networks and the chasma margins are pristine. Short and poorly developed valleys intersect with a chasma tributary north of Ius Chasma. The chasma margins do not appear to be eroded by individual valleys. Many of these channels have tributaries exhibiting typical sapping morphologies. Sapping morphology is found in the Valles Marineris chasma walls that have formed between the early Hesperian and Amazonian (Lucchitta et al., 1992) with most recent activity in the western most region of Noctis Labrynthus (Masson, 1980). These tributaries incise late Hesperian basalt flows from Syria Planum volcanic sources (Witbeck et al., 1991). These large dendritic, dense valley networks which were also seen in the southern wall of Ius chasma are termed dense and other poorly 
developed valley networks are called sparse. The sparse networks, because of their size, relatively pristine condition and clear morphological characteristics, appear to be more clearly associated with one class of formation processes.

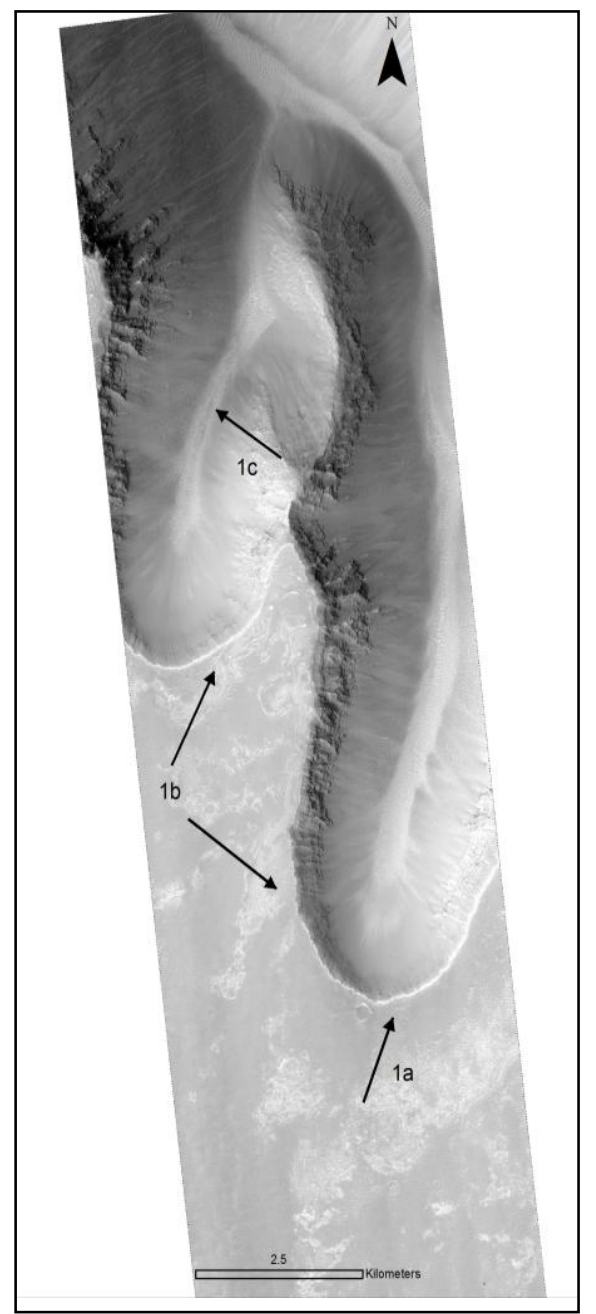

Fig. 2. HiRISE subset image south of Ius chasma have 1a) Steep theatre shaped headwalls $1 \mathrm{~b}$ ) short, stubby tributaries joining long main valley 1c) V-shaped valleys

The morphology of tributary channels and dense valley networks provide clues about their formation. First, the main channel do appear to have been eroded by groundwater activity in the dense valley networks and their margins are notched where valley networks intersect them and several tributary channels joins individual dense valley network segments. These observations suggest that tributary channels postdate dense valley network formation in this region. Our analysis (with HRSC imagery) of the valley networks suggests that pristine segments do occur along the channel but at some nick points where tributaries intersecting main valley system have been degraded because the tributary channel walls and floors carried deposits related to dense valley network activity. Additionally, most of the pristine segments identified by (Baker and Partridge 1986) are somewhat degraded relative to the large sparse valley networks.

Release of groundwater in large amount (Baker et al., 1992) might be the cause of origin of outflow channel and dimensions indicate discharges of about (Komar, 1979; Carr, 1979; Baker,
1982; Robinson and Tanaka, 1990; Dohm et al., 2001) two orders of magnitude larger than the largest known flood events on the Earth (the Channeled Scabland or the Chuja Basin flood in Siberia; Baker, 1973; Baker et al., 1992). Louros valles formation might include groundwater under high artesian pressure confined below a permafrost zone which may break out, triggered by events which disrupt the permafrost seal (e.g., such as impacts, faults, or dikes) either by breaking the surface (e.g., Head et al., 2003) or sending a large pressure pulse through the aquifer (Carr, 1979, 1996,). A water release process through melting of ground ice by volcanic heat is also another cause of groundwater seepage (Baker et al., 1991).

\subsubsection{Sapping model}

Sapping model for the development of branched valleys is postulated in this study based on morphometric evidences such as valley networks, longitudinal valleys and valley wall networks are similar to those of terrestrial stream networks in which sapping processes are dominant and features like steep theater shaped valley headwalls, hanging tributary valleys, long main valleys with short stubby tributaries (Figure 2), irregular angles of channel junction and valley width (upstream part) that remain nearly constant in downstream direction (Pieri, 1980; Baker, 1982; Laity and Malin, 1985).

When erosion creates slopes steeper than the maximum stable angle for loose material, downslope slumping occurs. Erosion by sapping tends to produce steep-sided U-shaped valleys of fairly uniform width with box-like, "theater-shaped" headwalls. The more common branching of V-shaped valleys produced by overland water flows that become wider with distance from their source. Groundwater is assumed to infiltrate uniformly over the landscape and to emerge in low lying areas. This emerged groundwater will erode the surface materials by the same process as fluvial erosion on the surface of the Earth. Water seeps from between layers of rock on the wall of a cliff, crater, or other type of depression. An alcove forms above the site of seepage as water comes out of the ground and erodes the material from which it is seeping. The erosion of material at the site of seepage causes rock and debris on the slope above this area to collapse and slide downhill, creating the alcove. The channel forms from water and debris running down the slope from the seepage area. The point where the top of the channel meets the bottom of the alcove is, in many cases, the site where seepage is occurring. The aprons are the down-slope deposits of ice and debris that were moved down the slope and through the channel. Whether any water likely in the form of ice persists in these deposits were not revealed.

There is a limit as to how much water actually makes it to the bottom of the slope in liquid form and most of the water by the time it reaches the bottom of the slope has probably either evaporated or frozen. However, the transported material might have been deposited in area near intersection forming Ushaped valleys (Figure 3 ). Some headward tributary channels in south and north of Ius Chasma do, however, coincide to some degree with the main chasma floor. This indicate that dense network and tributary channel formation were of the same period. but the lack of erosional or depositional forms in the channel does not support this view. However, depression of the valley networks apparently shallow in the Ius Chasma region, may have locally lowered the terrain enough to influence the subsequent headward migration of the tributary 
channels. We noted that mass wasting and other non-fluvial processes may have caused the superposition of observed valley morphologies, making their relative timing more difficult to assess. Valleys exhibit a narrow V shape at their origin point. The channel rims do not exhibit signs of erosion resulting from fluvial activity in the valleys. Moreover, it is clear that surface runoff is not influenced valley formation, since they do exhibit the well-developed dendritic form of the larger southern Ius Chasma networks. An important characteristic of groundwater sapping is that they form primarily on lowlands and on highly cratered southern hemisphere as well as on the elevated inter-crater plains.

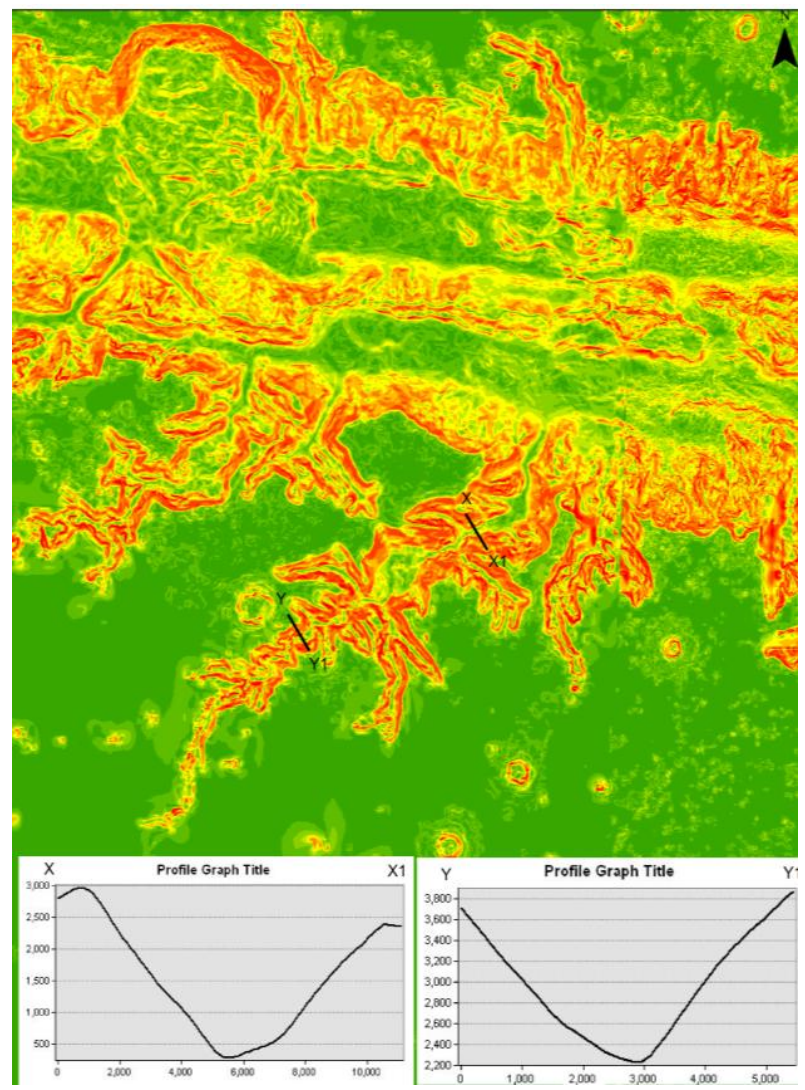

Fig. 3 A profile traversing the channel (elevation data) shows that the valleys forming $\mathrm{U}$ shaped $(\mathrm{X}-\mathrm{X} 1)$ and $\mathrm{V}$ shaped $(\mathrm{Y}-$ Y1).

Based on the evaluation of high-resolution Mars Observer Camera (MOC) images, Malin and Carr (1999) concluded that the valleys were formed by fluid erosion, and in most cases the source was groundwater. Alternatively, some heat may have been provided by high global (Carr and Head, 2003) or local (Travis et al., 2003) heat flux and melting of surface snowpack or ground ice. Relatively young small-scale alcove-like gullies combined with small channels and aprons in the walls of some impact craters indicate that groundwater seepage or short-term surface runoff may occur under recent climatic conditions (Malin and Edgett, 2000; Gaidos, 2001; Mellon and Phillips, 2001; Andersen et al., 2002; Mangold et al., 2003).

\subsection{Collapsed linear pits}

In places north of Valles Marineris, the alignments of these linear pits are parallel to shallow trough of Valles Marineris (figure 4). This landscape created when parts of Mars crust collapsed and it is thought that removal of fluid under its own weight caused irregularly shaped, variously-sized blocks of crust on depression floor. Within Valles Marineris pit chains were found primarily in south of coprates chasma, south of Tithonium Chasma. Some of these pits should not be confused with crater pits because craters always have ejecta blankets around them and a small mound in their centres. The floor of subsidence pits have very flat surface, and they have no ejecta where their walls intersect the surrounding plains. These pit chains shows signature with steep walls where is often conical can range in size from small pits at eastern tithonium chasma to large depression in Hebes and Juventae Chasmata.

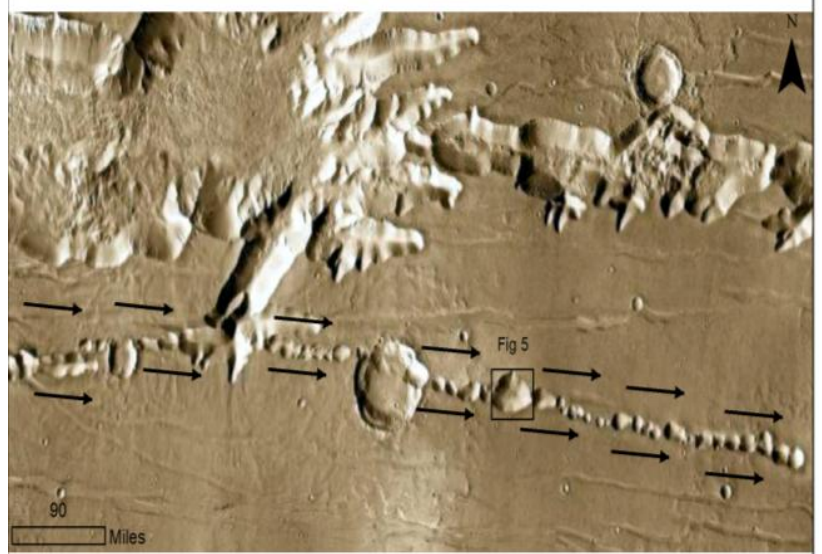

Fig. 4 HiRISE IR mosaic subset image shows the linearly collapsed pits.

\subsubsection{Possible origin of collapsed pits}

Various hypotheses have been proposed for the development of these linear pits. Tanaka and Golombek (1989), Tanaka et al. (1989) and Banerdt et al. (1992) suggested that those within Valles Marineris, Noctis Labyrinthus and Tantalus Fossa, to the east of Alba Patera, are underlain by tension cracks extending to the depth of the lithosphere. The surface graben are modeled as the surface manifestations of these faults at depth (Tanaka and Golombek, 1989). Once formed, these tension fractures are inferred to be widened by weathering, fluvial, mass-wasting, and aeolian processes. Tanaka and Golombek (1989) argue against volcanic processes as a formation mechanism for pit chains but however because there is an presence of volcanics, Tharis bulge (which houses biggest volano on Mars Olympus mons) north west of Valles Marineris suggested withdrawal of magma from this region might have caused the subsidence. However, the pit chains are not found throughout Valles Marineris, but at few places characterized by linear geometry, indicating that they may well be associated with an subsurface (Schultz, 1989). Mege and Masson (1996a) discussed the rift nature of Valles Marineris. Hence we can conclude that these pit chains were formed due to collapsing. A water release process through melting of ground ice by volcanic heat may also operate (Baker et al., 1991).

The small pits might have been formed by a withdrawal of ice, and the larger ones, which we postulate formed as a consequence of a surface collapse from the top and consider 
that all the pits are initially small but broadened by geomorphologic processes and mass-wasting events into larger coalesced features. These pits are interpreted to understand that ground ice has been removed from beneath the rigid upper crust. Another possible reason for the formation of pits was that there was sufficient available magma on Marian crust for such formation to continue with the building of a volcano. Hence, the presence of volcanic formations does necessarily indicate that the pit chains were formed by magma removal processes, because the eruption would simply cease when all the magma was consumed and evidence of biggest volcano was also visible near to this location.

It is much more likely that the larger pit chain were formed by collapsing processes involving mainly ground water. The main reason for this proposal is that the pits commonly occur in irregular sizes, from large to small in the west-to-east direction (see Figure 5). if the pit chain were conical produced by the withdrawal of water within the crust, the pits would most likely be laterally disordered in their sizes, depending on the local availability of water or ice-rich permafrost. Near this location there is a repetition in the sizes of linear groups of pits

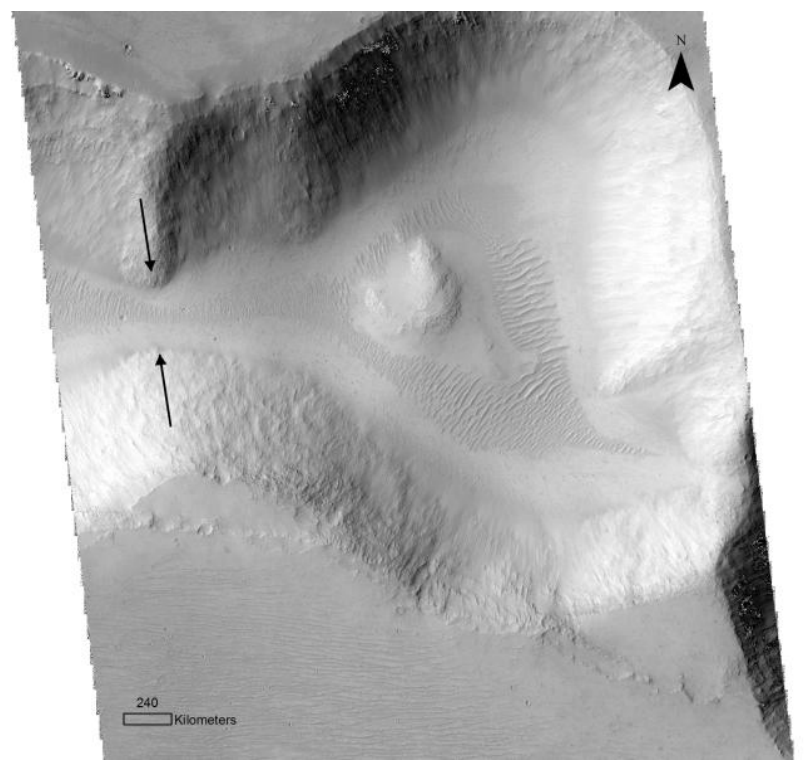

Fig. 5 HiRISE image having conical depressions Pits joining together in arrows. Aeolian ripples can been observed in floor.

from small to large, with the largest pit being at the intersection between the two pits. Within the same image an enechelon pattern in the pit chains was observed. Each new section of the enechelon structure begins with a large pit chain. We infer that these patterns may be connected to the episodic movement and withdrawal of magma.

\section{CONCLUSION}

We have analyzed branched valleys and pit chains that are present around the Ius chasma using DTMs and high resolution Mars orbiter data. Valleys were common in many areas of Mars, especially in southern highlands terrain and along the Valles Marineris. We found that the morphometry of the Martian branched valleys along Valles Marineris are very similar to the morphometry of experimentally formed sapping valleys (Kochl et aL, 1985). Although, we concur with previous researchers on the sapping model for formation of the branched valleys, lack of evidences such as source point of the groundwater episodic burst and absence of alluvial fan in the floor of the Valles Marineris are yet to be explained to convincingly validate the sapping model as the main cause of the formation of branched valleys.

The explanation of the sizes of linearly arranged pits can be obtained by considering the processes occurred due to subsidence. The smaller pits were expected as a result of collapse of surface rocks into the space created by the withdrawal of groundwater. The larger ones have volumes consistent with much larger scale collapse when a substantial local magma was withdrawn. The variation of size within groups of the be pits and of the location and spacing between groups, may be due to the presence and distribution of subsurface ice or water. Alternatively, there are some indications that the pits distribution patterns may be related to the distribution of local magma to Tharis bulge formation.

\section{REFERENCES}

Andersen, D. T., W. H. Pollard, C. P. McKay, and J. Heldmann 2002, Cold springs in permafrost on Earth and Mars Journal of Geophysics Research.,107 (E3), 5015, doi:10.1029/2000JE001436.

Baker, V.R., Carr, M.H., Gulick, V.C., Williams, C.R., and Marley, M.S. 1992. Channels and valley networks. In Mars, ed. H. Kieffer, B. Jakosky, C. Snyder, and M. Matthews. Tucson: University of Arizona Press,pp. 493-522.

Baker, V.R. (1982). The channels of Mars. Austin: University of Texas Press.

Banerdt, W. B., M. P. Golombek, and K. L. Tanaka, 1992,Stress and tectonics on Mars, in Mars, edited by H. H. Kieffer et al., chap. 8, pp. 249-297, University of Arizona. Press, Tucson,.

Battistini, R.: 1990, 'La d6stabilisation de l'hydrolithosph re par le volcanisme et le flux de chaleur interne: un facteur essentiel de la morphog6nbse martienne', La Terre et le Hommes (Publ. Faculte des Lettres et Sciences Humaines de Clermont-Ferrand) nouveUe sirie 32, 335-48

Carr, M. H. 1979, Formation of Martian flood features by release of water from confined aquifers, Journal of Geophysics Research, 84, 2995-3007.

Carr, M. H. 1996, Water on Mars, Oxford University Press, New York.

Carr, M. H., and J. W. Head III 2003, Basal melting of snow on early Mars: A possible origin of some valley networks, Journal of Geophysics Research,Lett.,30(24), 2245, doi:10.1029/2003GL018575.

Croft, S. K.: 1989, 'Mars' Canyon Systems: Problems of Origin', Abstract. 4th International. Confernce. on Mars, Tucson,pp. 88-89. 
Frey, H.: 1979, 'Martian Canyons and African Rifts: Structural Comparisons and Implications'. Icarus 37, 142-55.

Hartmann,W.k.,1974 Geological observations of martian arroyos. Journal of Geophysics Research. 79:pp.3951-3957.

Dohm, J.M., Ferris, J. C., Baker, V.R. et al. 2001. Ancient drainage basin of the Tharsis region, Mars: potential source for outflow channel systems and putative oceans or paleolakes. Journal of Geophysical Research, 106 (E12), 32943-58.

Gaidos, E. J. 2001, Cryovolcanism and the recent flow of liquid water on Mars, Icarus, 153, 218-223.

Kochel, R. C., A.D. Howard, and C. McLane, 1985,Channel networks developed by groundwater sapping in fine-grained sediments: analogs to some Martian valleys, in Models in Geomorphology, edited by M. Woldenberg, pp. 313-341, Allen and Unwin, Boston.

Kochel, R. C., and J. Piper (1986), Morphology of large valleys on Hawaii: Evidence for groundwater sapping and comparisons with Martian valleys,Proc. Lunar Planetary Science Conference. 17th, Part 1, Journal of Geophysics Research.,91, suppl.,E175-E192

Komar, P.D. (1979). Comparison of the hydraulics of water flows in Martian outflow channels with flows of similar scale on Earth. Icarus, 37, 156-81.

Lucchitta, B. K., A. S. McEwen, G. D. Clow, P. E. Geissler, R. B. Singer, R. A. Schultz, and S. W. Squyres 1992, The channel system on Mars, in Mars, edited by H. H. Keiffer et al., pp. 453-492, University of Arizona. Press, Tucson.

Laity, J. E., and M. C. Malin 1985, Sapping processes and the development of theater-headed valley networks on the Colorado Plateau, Geological.Society of America. Bull., 96,pp. 203-217.

Lucchitta, B. K.: 1989, 'Interior Structure of Valles Marineris, Mars', Abstr. 20th Lunar and Planetary Science Conference. 590-91.

Malin, M.C. and Carr, M.H. 1999. Groundwater formation of Martian valleys. Nature, 397, 589791.

Malin, C., and K. S. Edgett (2000), Evidence for recent groundwater see-page and surface runoff on Mars, Science, $288,2330-2335$.

Mangold, N., F. Costard, and F. Forget (2003), Debris flows over sand dunes on Mars: Evidence for liquid water, Journal of Geophysics Research 108(E4), 5027, doi:10.1029/2002JE001958.

Mege, D., and P. Masson,;1996a. Amounts of crustal stretching in Valles Marineris, Mars, Planetary Space Science.,44, 749782.

Mege, D., and P. Masson,;1996b A plume tectonics model for the Tharsis province, Mars, Planetary Space Science.,44, 1499-1546,.
Milton,D.J. 1973 Water and processes of degradation in martian landscape. Journal of Geophysics Research.78:40374047.

Moore, J. M., A. D. Howard, W. E. Dietrich, and P. M. Schenk 2003, Martian Layered Fluvial Deposits: Implications for Noachian Climate Scenarios, Geophysics Research letter., 30(24), 2292, doi:10.1029/ 2003GL019002.

Pieri, D. C. 1976, Martian valleys: Distribution of small valleys on the Martian surface, Icarus, 27, 25-50.

Pollack, J. B., J. F. Kasting, S. M. Richardson, and K. Poliakoff 1987, The case for a wet, warm climate on early Mars, Icarus, 71, 203-224.

Schultz, R. A., 1989.Strike-slip faulting of ridged plains near Valles Marineris, Mars, Nature, 341, 424-426.

Schultz, R. A., 1990.Complex early rifting in Valles Marineris: Results from preliminary geologic mapping of the Ophir Planum region of Mars, 1:50,0000 scale (abstract), Lunar Planetary Science.,XXI, 1103-1104,

Robinson, M.S. and Tanaka, K.L. (1990). Magnitude of a catastrophic flood event at Kasei Valles, Mars. Geology, 18, 902-5.

Schultz, R. A., 1991.Structural development of Coprates Chasma and western Ophir Planum, Valles Marineris rift, Mars, Journal of Geophysics Research.,96, 22,777-22,792,

Schultz, R. A., 1995.Gradients in extension and strain at Valles Marineris, Mars, Planetary Space Science,43, 15611566 ,

Schultz, R. A., 1997.Dual-process genesis for Valles Marineris basins and troughs on Mars (abstract),Lunar Planetary Science, XXVIII, 1263-1264.

Scott, D. H. and Tanaka, K. L.: 1986, 'Geological Map of the Western Equatorial Region of Mars, 1:15,000,000', USGS Misc. Inv. Series Map 1-1802A.

Sharp, R. P.: 1973, 'Mars: Troughed Terrain', Journal of Geophysical Research. 78, 4063-072.

Squyres, S. W., et al. (2004), In situ evidence for an ancient aqueous environment at Meridiani Planum, Mars, Science, 306, 1709-1714.

Tanaka, K. L., 1997.Origin of Valles Marineris and Noctis Labyrinthus, Mars, by structurally controlled collapse and erosion of crustal materials (abstract),Lunar Planetary. Sci ence.,XXVIII, 1413-1414,

Tanaka, K. L. 1986, The stratigraphy of Mars, Journal of Geophysical. Research. 91(B13),E139-E158

Tanaka, K. L., and M. P. Golombek,; 1989.Martian tension fractures and the formation of grabens and collapse features at Valles Marineris, Lunar Planetary Science Conference. 19th, 383-396, 
Tanaka, K. L., P. A. Davies, and M. P. Golombek, 1989.Development of grabens, tension cracks, and pits southeast of Alba Patera, Mars, in MEVTV Workshop on Tectonic Features on Mars, edited by T. R. Watters and M. P. Golombek, LPI Tech. Rep. 89-06, pp. 57-59, Lunar and Planetary Institute, Houston, Texas,

Travis, B. J., Rosenberg, N. D., Cuzzi, J. N., 2003. On the role of widespread subsurface convection in bringing liquid water close to Mars' surface. Journal of Geophysical Research (Planets) 108 (E4), 8040-8055.

Wise, D. U., Golombek, M. P., and McGilI, G. E.: 1979, 'Tharsis Province of Mars: Geologic Sequence, Geometry, and a Deformation Mechanism', Icarus 38, 456-72.

Witbeck, N. E., K. L. Tanaka, and D. H. Scott (1991), Geologic map of the Valles Marineris region, Mars, USGS Map I-2010. 